\title{
Prevalence and correlates of fire-setting in the United States: results from the National Epidemiological Survey on Alcohol and Related Conditions
}

\author{
Michael G. Vaughn ${ }^{\mathrm{a}, *}$, Qiang Fu ${ }^{\mathrm{b}}$, Matt DeLisi ${ }^{\mathrm{c}}$, John Paul Wright ${ }^{\mathrm{d}}$, Kevin M. Beaver ${ }^{\mathrm{e}}$, \\ Brian E. Perron ${ }^{\mathrm{f}}$, Matthew O. Howard ${ }^{\mathrm{g}}$ \\ ${ }^{a}$ School of Social Work and Department of Community Health, Division of Epidemiology, School of Public Health, \\ Saint Louis University, St. Louis, MO, USA \\ ${ }^{\mathrm{b}}$ Department of Biostatistics, School of Public Health, Saint Louis University, St. Louis, MO, USA \\ ${ }^{\mathrm{c} C r i m i n o l o g y}$ and Criminal Justice Studies, Department of Sociology, Iowa State University, Ames, IA, USA \\ ${ }^{\mathrm{d}}$ Division of Criminal Justice, University of Cincinnati, Cincinnati, OH, USA \\ ${ }^{\mathrm{e}}$ College of Criminology and Criminal Justice, Florida State University, Tallahassee, FL, USA \\ ${ }^{\mathrm{f}}$ School of Social Work, University of Michigan, Ann Arbor, MI, USA \\ ${ }^{\mathrm{g}}$ School of Social Work, University of North Carolina, Chapel Hill, NC, USA
}

\begin{abstract}
Fire-setting is a serious and costly form of antisocial behavior. Our objective in this study was to examine the prevalence and correlates of intentional fire-setting behavior in the United States. Data were derived from a nationally representative sample of US residents 18 years and older. Structured psychiatric interviews $(\mathrm{N}=43$ 093) were completed by trained lay interviewers between 2001 and 2002 . Fire-setting as well as mood, anxiety, substance use, and personality disorders of the Diagnostic and Statistical Manual of Mental Disorders, Fourth Edition were assessed with the Alcohol Use Disorder and Associated Disabilities Interview Schedule (Diagnostic and Statistical Manual of Mental Disorders, Fourth Edition) version. The prevalence of lifetime fire-setting in the US population was $1.0 \%$. Respondents who were men, white, 18 to 35 years old, born in the United States, and living in the western region of the United States had significantly higher rates of firesetting than their counterparts. Fire-setting was significantly associated with a wide range of antisocial behaviors. Multivariate logistic regression analyses identified strong associations between lifetime alcohol and marijuana use disorders, conduct disorder, antisocial and obsessive-compulsive personality disorders, and family history of antisocial behavior. Intentional illicit fire-setting behavior is associated with a broad array of antisocial behaviors and psychiatric comorbidities. Given the substantial personal and social costs related to arson, prevention and treatment interventions targeting fire-setters potentially could save lives and property.
\end{abstract}

(C) 2010 Elsevier Inc. All rights reserved.

\section{Introduction}

Fire-setting is a serious and costly form of antisocial behavior that results in hundreds of fatalities each year and property losses estimated in the hundreds of millions to more than $\$ 2$ billon annually [1,2]. Fire-setting is often used interchangeably with the legal term "arson," which is the intentional setting of fire with the intent to defraud or damage. However, fire-setting is a broader behavioral phenotype with important forensic, psychiatric, and criminological implications $[3,4]$. With the exception of "status offenses," fire-setting is the only crime in the United States

\footnotetext{
* Corresponding author. Tegeler Hall, St. Louis, MO 63103. Tel.: +1 314977 2718; fax: +1 3149772731 .

E-mail address: mvaughn9@slu.edu (M.G. Vaughn).
}

that is more commonly perpetrated by juveniles than adults, and the bulk of prior research has investigated the etiology of fire-setting in childhood and adolescence. Studies indicate that fire-setting is strongly correlated with family dysfunction, a history of abuse, school difficulties, antisocial traits including impulsivity and hostility, and co-occurring delinquent behaviors [5-14]. Along with enuresis and animal cruelty, fire-setting forms the "MacDonald Triad," which is a conceptual model of violence risk that has been linked to multiple homicide, homicide, and sexual offending $[15,16]$. Fire-setting is a sign of pyromania, which is characterized by repeated fire-setting, tension or affective arousal before setting fires, fascination or attraction to fire, gratification when setting, witnessing, or participating in the aftermath of fire, and expressive motivations for fire-setting [17]. 
Despite the apparent importance of fire-setting behavior to psychiatry and criminology, its epidemiology is largely unknown. For instance, the Diagnostic and Statistical Manual of Mental Disorders, Fourth Edition, Text Revision $(D S M-I V-T R)$ describes the prevalence of pyromania as "apparently rare."[17] Estimates of the prevalence of firesetting vary widely. Kolko and Kazdin's [18] study of 300 psychiatrically disturbed children found prevalence rates of $19.4 \%$ among outpatients and $34.7 \%$ among inpatients. A recent evaluation of 4 cohorts of arson offenders in England and Wales in $1951(\mathrm{n}=74), 1963$ to $1965(\mathrm{n}=1352), 1980$ to $1981(\mathrm{n}=5584)$, and 2000 to $2001(\mathrm{n}=3335)$ showed increasing annual arson prevalence from $4.5 \%$ in 1951 to $10.7 \%$ in 1980 to 1981 [19]. Even in large studies of criminal careers including those with prospective birth cohort designs, fire-setting behavior and offenders who commit fire-setting are often ignored [20].

\subsection{Study purpose}

The purpose of this study was to examine the prevalence and correlates of intentional fire-setting in a nationally representative sample of US adults. The primary aims were to (1) examine the prevalence of lifetime fire-setting overall and in relation to sociodemographic characteristics, antisocial behaviors, and lifetime mood, anxiety, substance use, and personality disorders and (2) to estimate the strength of the associations between these characteristics and fire-setting in controlled multivariate analyses.

\section{Materials and methods}

\subsection{Participants}

Study findings are based on data from the 2001-2002 National Epidemiologic Survey on Alcohol and Related Conditions (NESARC). The NESARC is a nationally representative sample of 43093 noninstitutionalized US residents 18 years and older [21]. The survey gathered information on alcohol use and comorbid conditions from individuals living in households and group settings such as shelters, college dormitories, and group homes in all 50 states, and the District of Columbia. NESARC used a multistage cluster sampling design, oversampling young adults, Hispanics, and African Americans in the interest of obtaining reliable statistical estimation in these populations and to ensure appropriate representation of racial/ethnic subgroups, with an overall response rate of $81 \%$. Data were weighted at the individual and household levels to adjust for oversampling and nonresponse on demographic variables (ie, age, race/ethnicity, sex, region, and place of residence). Data were also adjusted to be representative (based on region, age, race, and ethnicity) of the US adult population as assessed during the 2000 Census. Study participants provided fully informed consent. The US Census Bureau and the US Office of Management and Budget approved the research protocol and informed consent procedures.

\subsection{Diagnostic assessment and sociodemographic measures}

Data were collected through face-to-face interviews conducted by US Census workers trained by the National Institute on Alcohol and Alcoholism and US Census Bureau. Interviewers administered the Alcohol Use Disorder and Associated Disabilities Interview Schedule-DSM-IV version, shown to have good-to-excellent reliability in assessing alcohol and drug use in the general population [22,23].

Data on fire-setting were based on an item embedded in the antisocial personality disorder interview module. All NESARC participants were asked the following question: "In your entire life, did you ever start a fire on purpose to destroy someone else's property or just to see it burn?" NESARC respondents who answered "yes" were defined as having a history of fire-setting. The test-retest reliability for the antisocial personality disorder diagnosis is adequate $(r=$ 0.69) [21]. The internal consistency reliability for the antisocial personality disorder symptoms set is 0.86 [24].

In addition to antisocial personality disorder, other personality disorders assessed included avoidant, dependent, obsessive-compulsive, paranoid, schizoid, and histrionic disorders. Consistent with prior research [25-27], personality disorder diagnoses reflected long-standing impairments, characteristic patterns of behavior, and exclusion of cases where substance use intoxication or withdrawal, other medication use, or physical illnesses could have affected behavior. Numerous control variables were used to reduce confounding, including lifetime alcohol (alcohol abuse/ dependence) and drug (abuse/dependence on heroin, hallucinogens, cocaine/crack, marijuana, stimulants, painkillers, tranquilizers, and sedatives) use disorders, nicotine dependence, pathological gambling, and lifetime DSM-IV mood (major depression, dysthymia, and bipolar disorder) and anxiety (social phobia, generalized anxiety disorder, panic disorder, and specific phobia) disorders. Family history of antisocial behavior based on any parental or sibling history of antisocial behavior was also assessed. Response categories for region of residence in United States, urbanicity, race/ethnicity, sex, age, marital status, educational background, unemployment status, and individual and family income are listed in Table 1.

\subsection{Statistical analyses}

Weighted prevalence estimates and SEs were computed using SUDAAN Version 9.0 [28]. This system implements a Taylor series linearization to adjust SEs of estimates for complex survey sampling design effects including clustered data. Multivariate logistic regression analyses were conducted with simultaneous entry of sociodemographic covariates and psychiatric variables. Adjusted odds ratios (ORs) and 95\% confidence intervals (CIs) are presented to 
Table 1

Sociodemographic characteristics of adult NESARC respondents with and without a lifetime history of fire-setting behavior

\begin{tabular}{|c|c|c|c|}
\hline Characteristic & Fire-setters $(n=407), \%(C I)$ & Non-fire-setters $(\mathrm{n}=41552), \%(\mathrm{CI})$ & $\mathrm{OR}^{\mathrm{a}}(95 \% \mathrm{CI})$ \\
\hline \multicolumn{4}{|l|}{ Sex } \\
\hline Men & $82.08(77.45-85.93)$ & $47.43(46.81-48.06)$ & $4.96(3.72-6.60)$ \\
\hline Women & $17.92(14.07-22.55)$ & $52.57(51.94-53.19)$ & 1.00 \\
\hline \multicolumn{4}{|l|}{ Race } \\
\hline Hispanic & $7.28(4.73-11.04)$ & $11.57(9.32-14.29)$ & $0.49(0.26-0.92)$ \\
\hline \multicolumn{4}{|l|}{ Asian/Alaska/Indian } \\
\hline Native American & $3.66(1.93-6.85)$ & $6.52(5.57-7.63)$ & $0.53(0.25-1.11)$ \\
\hline African American & $8.60(6.02-12.15)$ & $11.02(9.80-12.37)$ & $0.64(0.42-0.96)$ \\
\hline White & $80.46(74.92-85.01)$ & $70.88(67.61-73.96)$ & 1.00 \\
\hline \multicolumn{4}{|l|}{ Nativity } \\
\hline Born in the United States & $94.20(88.70-97.11)$ & $85.33(82.07-88.07)$ & $2.59(1.01-6.64)$ \\
\hline Born in a foreign country & $5.80(2.89-11.30)$ & $14.67(11.93-17.93)$ & 1.00 \\
\hline \multicolumn{4}{|l|}{ Age $(y)$} \\
\hline $65+$ & $4.18(2.42-7.12)$ & $16.39(15.73-17.08)$ & $0.16(0.08-0.29)$ \\
\hline $50-64$ & $13.39(10.16-17.46)$ & $21.15(20.62-21.68)$ & $0.39(0.28-0.54)$ \\
\hline $35-49$ & $31.26(25.60-37.53)$ & $31.08(30.44-31.72)$ & $0.64(0.47-0.87)$ \\
\hline $18-34$ & $51.17(45.01-57.30)$ & $31.39(30.51-32.28)$ & 1.00 \\
\hline \multicolumn{4}{|l|}{ Education } \\
\hline Lower than high school level & $12.90(9.63-17.06)$ & $15.54(14.60-16.53)$ & $1.10(0.77-1.57)$ \\
\hline High school graduate & $27.37(21.83-33.72)$ & $29.34(28.24-30.47)$ & $0.95(0.69-1.30)$ \\
\hline Some college or higher & $59.73(53.84-65.35)$ & $55.11(53.84-56.37)$ & 1.00 \\
\hline \multicolumn{4}{|l|}{ Income } \\
\hline $0-19$ & $24.14(19.01-30.15)$ & $23.44(22.49-24.42)$ & $1.34(0.87-2.06)$ \\
\hline 20 & $16.33(12.35-21.28)$ & $20.15(19.49-20.83)$ & $0.93(0.62-1.41)$ \\
\hline 35 & $35.42(29.53-41.79)$ & $32.15(31.50-32.82)$ & $1.16(0.83-1.63)$ \\
\hline 70 & $24.10(19.17-29.84)$ & $24.26(22.89-25.68)$ & 1.00 \\
\hline \multicolumn{4}{|l|}{ Marital status } \\
\hline Never married & $34.39(28.53-40.77)$ & $20.53(19.60-21.50)$ & $1.12(0.80-1.57)$ \\
\hline Widowed/separated/divorced & $11.11(8.10-15.06)$ & $17.42(16.96-17.90)$ & $1.03(0.70-1.52)$ \\
\hline Married/Cohabitating & $54.50(48.23-60.62)$ & $62.04(61.10-62.98)$ & 1.00 \\
\hline \multicolumn{4}{|l|}{ Urbanicity } \\
\hline Central city & $33.38(26.63-40.90)$ & $29.39(25.28-33.87)$ & $1.23(0.92-1.65)$ \\
\hline Rural/Suburban & $66.62(59.10-73.37)$ & $70.61(66.13-74.72)$ & 1.00 \\
\hline \multicolumn{4}{|l|}{ Region } \\
\hline Northeast & $12.70(7.61-20.45)$ & $19.79(13.87-27.45)$ & $0.42(0.28-0.61)$ \\
\hline Midwest & $22.09(15.88-29.85)$ & $23.19(17.44-30.13)$ & $0.54(0.38-0.76)$ \\
\hline South & $33.35(25.49-42.27)$ & $35.14(28.96-41.86)$ & $0.60(0.43-0.84)$ \\
\hline West & $31.86(23.01-42.24)$ & $21.88(15.68-29.67)$ & 1.00 \\
\hline
\end{tabular}

${ }^{\text {a }}$ OR values in bold are statistically significant.

reflect association strength and significance. Adjusted ORs were considered significant only if associated CIs did not include the value 1.0.

\section{Results}

\subsection{Sociodemographic characteristics}

The overall prevalence of fire-setting in the US population was $1.0 \%$. Table 1 provides comparisons of persons with and without a lifetime history of fire-setting across NESARC sociodemographic characteristics. Unadjusted analyses revealed that persons reporting a lifetime history of firesetting were more likely to be men (OR, 4.96; 95\% CI, 3.726.60), born in the United States (OR, 2.59; 95\% CI, 1.016.64), and less likely to be African American (OR, 0.64; 95\% CI, 0.42-0.96), and Latino/Hispanic (OR, 0.49; 95\% CI, 0.26-0.92). Compared with respondents between the ages of
18 and 34 years, persons 35 years and older were less likely to report intentional fire-setting. Compared with persons from other regions of the country (Northeast, Midwest, South), respondents from the West were more likely to report fire-setting. There were no significant differences with respect to education, income, marital status, and urbanicity.

\subsection{Fire-setting and associated antisocial behaviors}

The prevalence of all antisocial behaviors was higher among persons with a lifetime history of fire-setting compared with persons without such a history (Table 2). The most prevalent behaviors for persons with a history of fire-setting were staying out late without permission (62.62\%; CI, 56.52\%-68.34\%), cutting class and leaving without permission (61.42\%; CI, 55.47\%-67.04\%), and shoplifting (58.16\%; CI, 51.79\%-64.26\%). The least prevalent behavior was forcing someone to have sex $(1.42 \%$; 
Table 2

Lifetime prevalence of antisocial behaviors in adults with and without a lifetime history of fire-setting behavior

\begin{tabular}{|c|c|c|c|}
\hline Behavior & $\begin{array}{l}\text { Fire-setters }(n=407) \\
\%(95 \% \text { CI })\end{array}$ & $\begin{array}{l}\text { Non-fire-setters }(\mathrm{n}=41552) \\
\%(95 \% \text { CI })\end{array}$ & $\mathrm{OR}^{\mathrm{a}}(95 \% \mathrm{CI})$ \\
\hline \multicolumn{4}{|l|}{ Violent } \\
\hline Force someone to have sex & $1.42(0.59-3.40)$ & $0.12(0.09-0.17)$ & $18.36(13.73-24.55)$ \\
\hline Get into lots of fights that you started & $21.04(16.51-26.51)$ & $2.61(2.38-2.85)$ & $11.57(4.38-30.53)$ \\
\hline $\begin{array}{l}\text { Get into a fight that came to swapping } \\
\text { blows with husband/wife or } \\
\text { boyfriend/girlfriend }\end{array}$ & $18.91(15.08-23.44)$ & $6.50(6.07-6.96)$ & $9.96(7.17-13.84)$ \\
\hline Use a weapon in a fight & $21.32(16.80-26.66)$ & $2.47(2.26-2.70)$ & $3.35(2.49-4.51)$ \\
\hline Hit someone so hard that you injure them & $34.91(29.22-41.06)$ & $5.69(5.29-6.11)$ & $10.69(7.81-14.64)$ \\
\hline Harass/threaten/blackmail someone & $21.50(16.48-27.55)$ & $1.50(1.33-1.69)$ & 8.89 (6.71-11.79) \\
\hline Bully/push people & $34.11(28.50-40.19)$ & $5.93(5.55-6.34)$ & $8.20(6.25-10.77)$ \\
\hline Hurt an animal on purpose & $17.61(12.99-23.44)$ & $1.64(1.48-1.83)$ & $12.79(8.85-18.49)$ \\
\hline Rob/mug someone or snatch a purse & $4.57(2.82-7.33)$ & $0.25(0.19-0.32)$ & $19.36(10.89-34.43)$ \\
\hline $\begin{array}{l}\text { Do things that could have easily } \\
\text { hurt you/others }\end{array}$ & $53.08(46.79-59.27)$ & $13.69(12.74-14.70)$ & 7.13 (5.51-9.22) \\
\hline \multicolumn{4}{|l|}{ Nonviolent } \\
\hline Cut class and leave without permission & $61.42(55.47-67.04)$ & $21.49(20.77-22.24)$ & $5.81(4.50-7.51)$ \\
\hline Stay out late at night & $62.62(56.52-68.34)$ & $25.38(24.49-26.29)$ & $4.93(3.76-6.46)$ \\
\hline Run away from home overnight & $26.44(21.40-32.19)$ & $4.90(4.59-5.24)$ & $6.97(5.25-9.25)$ \\
\hline Be absent from work/school a lot & $32.84(26.84-39.45)$ & $6.60(6.23-7.00)$ & $6.91(5.17-9.25)$ \\
\hline $\begin{array}{l}\text { Quit a job without knowing where to } \\
\text { find another }\end{array}$ & $42.11(36.45-47.98)$ & $11.27(10.68-11.89)$ & $5.72(4.46-7.35)$ \\
\hline $\begin{array}{l}\text { Quit a school program without } \\
\text { knowing what to do next }\end{array}$ & $18.99(15.25-23.39)$ & $3.65(3.35-3.97)$ & $6.19(4.71-8.14)$ \\
\hline $\begin{array}{l}\text { Travel around more than } 1 \text { mo } \\
\text { without plans }\end{array}$ & $17.89(13.85-22.81)$ & $3.28(3.03-3.54)$ & $6.44(4.74-8.74)$ \\
\hline $\begin{array}{l}\text { Have no regular place to live at } \\
\text { least } 1 \mathrm{mo}\end{array}$ & $20.00(15.61-25.24)$ & $2.56(2.31-2.85)$ & $9.50(7.00-12.88)$ \\
\hline Live with others at least $1 \mathrm{mo}$ & $37.87(32.00-44.13)$ & $10.87(10.19-11.60)$ & $5.00(3.88-6.44)$ \\
\hline Lie a lot & $33.32(27.55-39.65)$ & $4.98(4.67-5.30)$ & $9.55(7.17-12.71)$ \\
\hline Use a false or made up name/alias & $19.63(15.06-25.17)$ & $1.95(1.78-2.13)$ & $12.29(8.85-17.07)$ \\
\hline Scam/con someone for money & $18.90(14.52-24.22)$ & $1.32(1.16-1.49)$ & $17.46(12.63-24.14)$ \\
\hline $\begin{array}{l}\text { Get } 3 \text { or more traffic tickets } \\
\text { for reckless driving/causing accidents }\end{array}$ & $23.39(18.90-28.58)$ & $8.52(7.89-9.20)$ & $3.28(2.45-4.39)$ \\
\hline $\begin{array}{l}\text { Have a driver's license } \\
\text { suspended/revoked }\end{array}$ & $26.42(21.75-31.70)$ & $7.57(7.06-8.11)$ & $4.39(3.36-5.72)$ \\
\hline Destroy others' property & $49.58(43.51-55.66)$ & $3.22(2.94-3.53)$ & $29.54(22.76-38.35)$ \\
\hline Fail to pay off your debts & $24.13(18.76-30.46)$ & $3.95(3.63-4.29)$ & 7.74 (5.56-10.78) \\
\hline Steal anything from others & $56.79(50.15-63.20)$ & $8.46(7.90-9.05)$ & $14.23(10.74-18.85)$ \\
\hline Forge someone's signature & $14.22(10.52-18.94)$ & $2.01(1.83-2.21)$ & $8.07(5.66-11.51)$ \\
\hline Shoplift & $58.16(51.79-64.26)$ & $10.80(10.11-11.52)$ & $11.48(8.82-14.96)$ \\
\hline Make money illegally & $27.90(22.49-34.05)$ & $2.48(2.25-2.74)$ & $15.19(11.12-20.76)$ \\
\hline
\end{tabular}

${ }^{a}$ OR values in bold are statistically significant.

CI, $0.59 \%-3.41 \%)$. The strongest associations between antisocial behaviors and fire-setting were found for destroying others' property (OR, 29.54; 95\% CI, 22.76-38.35), robbing/mugging someone or snatching a purse (OR, 19.36; 95\% CI, 10.89-34.43), and forcing someone to have sex (OR, 18.36; 95\% CI, 13.73-24.55).

\subsection{Multivariate logistic regression analysis examining associations between fire-setting and lifetime comorbidity}

Table 3 compares prevalence rates of lifetime psychiatric comorbidity for persons reporting and not reporting a history of fire-setting. Odd ratios are adjusted for sociodemographic factors (ie, race, sex, education, marital status, age, income, region, and urbanicity) and previously described lifetime
$D S M-I V$ psychiatric disorders. The most prevalent psychiatric disorders among persons with a history of fire-setting were any lifetime alcohol use disorder $(71.70 \%$; $\mathrm{CI}, 65.41 \%$ $77.24 \%)$, antisocial personality disorder $(51.46 \%$; CI, 45.64\%-57.24\%), marijuana use disorder (43.17\%; CI, 37.39\%-49.14\%), and nicotine dependence (42.95\%; CI, $36.89 \%-49.23 \%$ ). A family history of antisocial behavior was also highly prevalent among persons reporting a history of fire-setting (59.96\%; CI, 54.14\%-65.50\%). After adjustments, significant associations were found for any lifetime alcohol use disorder (OR, 1.55; 95\% CI, 1.08-2.22), marijuana use disorder (OR, 1.70; 95\% CI, 1.21-2.38), conduct disorder (OR, 13.85; 95\% CI, 8.51-22.53), obsessive-compulsive (OR, 1.92; 95\% CI, 1.35-2.74) and antisocial (OR, 12.38; 95\% CI, 8.93-17.18) personality 
Table 3

Psychiatric comorbidities of adults with and without a lifetime history of fire-setting behavior

\begin{tabular}{|c|c|c|c|}
\hline Comorbid psychiatric disorder & Fire-setters $(\mathrm{n}=407), \%(95 \% \mathrm{CI})$ & Non-fire-setters $(\mathrm{n}=41552), \%(95 \% \mathrm{CI})$ & Adjusted ORs ${ }^{\mathrm{a}}$, OR $(95 \% \mathrm{CI})$ \\
\hline \multicolumn{4}{|l|}{ Mood disorders } \\
\hline Major depressive disorder & $32.96(26.98-39.56)$ & $16.69(16.00-17.40)$ & $0.96(0.69-1.34)$ \\
\hline Bipolar disorder & $26.92(21.30-33.41)$ & $5.51(5.18-5.87)$ & $1.41(0.94-2.10)$ \\
\hline Dysthymia & $14.02(9.88-19.51)$ & $4.25(3.98-4.55)$ & $1.56(0.95-2.56)$ \\
\hline \multicolumn{4}{|l|}{ Anxiety disorders } \\
\hline Panic disorder & 8.34 (5.56-12.34) & $4.05(3.78-4.33)$ & $0.86(0.49-1.4 \mathrm{fs} 8)$ \\
\hline Social phobia & $10.70(6.96-16.11)$ & $5.03(4.64-5.45)$ & $0.72(0.44-1.19)$ \\
\hline Specific phobia & $18.61(14.15-23.01)$ & $9.51(8.92-10.14)$ & $1.10(0.76-1.58)$ \\
\hline Generalized anxiety disorder & $7.41(4.90-11.05)$ & $4.20(3.87-4.55)$ & $0.64(0.36-1.13)$ \\
\hline \multicolumn{4}{|l|}{ Substance use disorders } \\
\hline Alcohol use disorder & $71.70(65.41-77.24)$ & $29.91(28.41-31.46)$ & $1.55(1.08-2.22)$ \\
\hline Nicotine dependence & $42.95(36.89-49.23)$ & $17.62(16.66-18.62)$ & $0.93(0.68-1.26)$ \\
\hline Marijuana use disorder & $43.17(37.39-49.14)$ & $8.11(7.58-8.67)$ & $1.70(1.21-2.38)$ \\
\hline Other illicit drug use disorder & $31.31(26.16-36.96)$ & $5.00(4.62-5.41)$ & $1.35(0.94-1.94)$ \\
\hline Psychotic disorder & $2.92(1.73-4.88)$ & $0.77(0.67-0.90)$ & $0.88(0.41-1.87)$ \\
\hline Conduct disorder & $9.01(6.09-13.13)$ & $0.99(0.86-1.13)$ & $13.85(8.51-22.53)$ \\
\hline \multicolumn{4}{|l|}{ Personality disorders } \\
\hline Avoidant & $6.75(4.22-10.61)$ & $2.36(2.15-2.59)$ & $0.90(0.40-2.01)$ \\
\hline Dependent & $1.85(0.83-4.07)$ & $0.49(0.40-0.60)$ & $0.48(0.14-1.56)$ \\
\hline Obsessive-compulsive & $30.36(24.87-36.47)$ & $7.82(7.39-8.28)$ & $1.92(1.35-2.74)$ \\
\hline Paranoid & $17.24(13.07-22.39)$ & $4.37(4.07-4.69)$ & $1.20(0.75-1.90)$ \\
\hline Schizoid & $11.05(8.19-14.75)$ & $3.11(2.87-3.37)$ & $1.03(0.61-1.74)$ \\
\hline Antisocial & $51.46(45.64-57.24)$ & $3.18(2.92-3.45)$ & $12.38(8.93-17.18)$ \\
\hline Histrionic & $12.07(8.72-16.46)$ & $1.76(1.60-1.95)$ & $1.43(0.87-2.36)$ \\
\hline Pathological gambling & $2.75(1.52-4.91)$ & $0.41(0.34-0.49)$ & $1.53(0.63-3.73)$ \\
\hline Family history of antisocial behavior & $59.96(54.14-65.50)$ & $22.62(21.58-23.69)$ & $2.16(1.66-2.80)$ \\
\hline
\end{tabular}

${ }^{a}$ OR adjusted for sociodemographic variables, lifetime psychiatric disorders, and a family history of antisocial behavior. OR values in bold are statistically significant.

disorders, and family history of antisocial behavior (OR, 2.16; 95\% CI, 1.66-2.80).

\section{Discussion}

To our knowledge, this is the largest national epidemiological study examining the association between fire-setting and psychiatric diagnoses. Findings indicated that the prevalence of fire-setting varied by sociodemographic status, was associated with all antisocial behaviors, and after adjustments for numerous confounding variables, was associated with several lifetime psychiatric diagnoses. Specifically, the current investigation found that the prevalence of fire-setting was higher among males and lower among African Americans and Hispanics, persons 35 years and older, and persons living in the Northeast, Midwest, and South. Two additional empirical trends are particularly important. First, compared with persons who have not set fires, fire-setters engage in multiple forms of antisocial behavior spanning a range of social dimensions including school behavior, driving and traffic-related behavior, interpersonal relationships, and crime. As shown in Table 2, the ORs for serious forms of antisociality, such as cruelty to animals, robbery, forcible rape, assault, aggravated assault, and weapons use, are high. These findings support general theoretical viewpoints, which suggest that antisoci- ality is an omnibus disposition that is significantly related to problem behaviors across time and various settings [29,30]. Second, fire-setting was unrelated to income, educational attainment, marital status, urbanicity, mood disorders, anxiety disorders, and psychotic disorder. There was significant comorbidity between fire-setting and alcohol use disorder, marijuana use disorder, obsessive-compulsive personality disorder, and family history of antisocial behavior. These effects were relatively modest and ranged from ORs of 1.55 to 2.16. There was also comorbidity between fire-setting and conduct disorder (OR, 13.85; CI, 8.51-22.53) and fire-setting and antisocial personality disorder (OR, 12.38; CI, 8.93-17.18), and these effects were very strong. This suggests that persons who commit fire-setting are severely antisocial with important psychiatric impairments as suggested by prior research [10].

\subsection{Limitations}

As with other studies, current study findings require interpretation within the context of several limitations. One limitation is that the data are cross-sectional. As such, the findings cannot clarify the etiological relationship of firesetting to identified correlates. For example, alcohol abuse/ dependence may disinhibit neuroregulatory processes, making the expression of fire-setting behavior more likely or both alcohol abuse and fire-setting behavior may be caused, 
in part, by a third factor, such as dysregulated serotonergic neurotransmission. However, findings do suggest that the origins of fire-setting and psychopathology are intertwined. The prognostic relationship between fire-setting and psychiatric disorders will require longitudinal study designs beginning earlier in the life course. The age of onset of firesetting behavior is potentially important, and unfortunately, the NESARC does not provide data pertaining to the age at which fire-setting began. The NESARC excludes persons younger than 18 years and therefore relies on retrospective respondent recall of fire-setting over potentially long periods of time. This could lead to underreporting or to biased reporting with younger respondents recalling better than older respondents. This disparity could also reflect secular trends. Although the NESARC is a nationally representative sample, it is uncertain how the association between firesetting and psychiatric comorbidity would be similar or different if enriched correctional or clinical samples were used. In addition, the data on fire-setting did not include important contextual, situational, and precipitating information that is important to understanding fire-setting [1]. Furthermore, the single item on fire-setting does not permit us to distinguish between episodic versus chronic firesetting. Also, the stigmatized nature of fire-setting could well lead to underreporting of the behavior. Thus, the problem is likely to be larger than what the findings reveal-this is especially the case given that the behavior is illegal. Furthermore, theoretically, it would seem possible to start a fire just to see it burn and to do so in a way that was not illegal or dangerous. For example, camp fires are acts that are quite ordinary, particularly in the Western United States. Therefore, it is possible that the item capture's a lot of false positives for fire-setting. Future studies on fire-setting would benefit from including these natural history features in such assessments. Despite these limitations, findings from this study provide new and important epidemiological insights into the problem of fire-setting in the United States

\section{Acknowledgment}

NESARC was funded by the National Institute on Alcohol Abuse and Alcoholism with additional support provided by the National Institute on Drug Abuse. The authors are grateful for the support from National Institutes of Health grants: DA021405 (Dr. Howard) and K07CA104119 (Dr Fu).

\section{References}

[1] Putnam CT, Kirkpatrick JT. Juvenile fire setting: a research overview. Washington, DC: Office of Juvenile Justice and Delinquency Prevention; 2005

[2] Fineman KR. Arson. In: Hickey E, editor. Encyclopedia of murder \& violent crime. Thousand Oaks, CA: Sage; 2003. p. 26-32.

[3] Turvey BE. Fire and explosives: behavioral aspects. In: Turvey E, editor. Criminal profiling: an introduction to behavioral evidence analysis. 2nd ed. Amsterdam, Netherlands: Elsevier Academic Press; 2002. p. 391-410.
[4] Douglas JE, Burgess AW, Burgress AG, Ressler RK. Crime classification manual: a standard system for investigating and classifying violent crimes. San Francisco, CA: Jossey-Bass; 1992.

[5] Becer KD, Stuewig J, Herrera VM, McCloskey LA. A study of fire setting and animal cruelty in children: family influences and adolescent outcomes. J Amer Acad Child Adol Psych 2004;43:905-12.

[6] Soothill KL, Pope PJ. Arson: a 20-year cohort study. Med Sci Law 1973;13:127-38.

[7] Fineman KR. A model for the qualitative analysis of child and adult fire deviant behavior. Amer J of For Psych 1995;13:31-60.

[8] Cox-Jones C, Lubetsky MJ, Fultz SA, Kolko DJ. Case study: inpatient psychiatric treatment of a young recidivist firesetter. J Amer Acad Child Adol Psych 1990;29:936-41.

[9] Root C, MacKay S, Henderson J, Del Bove G, Warling D. The link between maltreatment and juvenile fire setting: correlates and underlying mechanisms. Child Abuse \& Neglect 2008;32:161-76.

[10] Repo E, Virkkunen M. Young arsonists: history of conduct disorder, psychiatric diagnoses and criminal recidivism. J For Psych \& Psychology 1997;8:311-20.

[11] Lindberg N, Holi MM, Tani P, Virkkunen M. Looking for pyromania: characteristics of a consecutive sample of Finnish male criminals with histories of recidivist fire setting between 1973 and 1993. BMC Psych 2005;5:47.

[12] Kazdin AE, Kolko DJ. Patient psychopathology and family functioning among childhood fire setters. J Abn Child Psychology 1986;14:315-29.

[13] Kolko DJ, Kazdin AE. Matchplay and fire setting in children: relationship to parent, marital, and family dysfunction. J Clin Child Psychology 1990;19:229-38.

[14] Virkunnen M, Eggert M, Rawlings R, Innoila M. A prospective followup study of alcoholic violent offenders and fire setters. Arch Gen Psychiatry 1996;53:523-9.

[15] MacDonald JM. The threat to kill. Am J Psychiatry 1963;120:125-30.

[16] Hellman DS, Blackman N. Enuresis, fire setting, and cruelty to animals: a triad predictive of adult crime. Am J Psychiatry 1966;122:1431-5.

[17] American Psychaitric Association. Diagnostic and Statistical Manual of Mental Disorders. 4th ed. Washington, DC: American Psychiatric Association; 2000. Text Revision.

[18] Kolko DJ, Kazdin AE. Prevalence of fire setting and related behaviors among child psychiatric patients. J of Consul Clin Psychology 1988;56:628-30.

[19] Soothill K, Ackerley E, Francis B. The criminal careers of arsonists. Med Sci Law 2004;44:27-40.

[20] DeLisi M. Extreme career criminals. Am J Crim Just 2001;25: 239-52.

[21] Grant BF, Dawson DA, Stinson FS, Chou PS, Kay W, Pickering R. The Alcohol Use Disorder and Associated Disabilities Interview Schedule-IV (AUDADIS-IV): reliability of alcohol consumption, tobacco use, family history of depression and psychiatric diagnostic modules in a general population sample. Drug Alc Depend 2003;71:7-16.

[22] Grant BF, Harford T, Dawson DA, Chou PS, Pickering RP. The Alcohol Use Disorder and Associated Disabilities Interview schedule (AUDADIS): reliability of alcohol and drug modules in a general population sample. Drug Alc Depend 1995;39:37-44.

[23] Hasin D, Carpenter KM, McCloud S, Smith M, Grant BF. The alcohol use disorders and associated disabilities interview schedule (AUDADIS): reliability of alcohol and drug modules in a clinical sample. Drug Alc Depend 1997;44:133-41.

[24] Blanco C, Grant J, Petry NM, Simpson HB, Alegria A, Liu S, et al. Prevalence and correlates of shoplifting in the United States: results from the National Epidemiologic Survey on Alcohol and Related Conditions (NESARC). Am J Psychiatry 2008;165:905-13.

[25] Grant BF, Stinson FS, Hasin DS, Dawson DA, Chou SP, Ruan WJ, et al. Co-occurrence of 12-month alcohol and drug use disorders and personality disorders in the United States: results from the National 
Epidemiologic Survey on Alcohol and Related Conditions. Arch Gen Psychiatry 2004;61:361-8.

[26] Grant BF, Hasin D, Stinson FS, Dawson DA, Chou PS, Ruan WJ, et al. Prevalence, correlates, and disability of personality disorders in the United States: results from the National Epidemiologic Survey of Alcohol and Related Conditions. J Clin Psychiatry 2004;65:948-58.

[27] Goldstein RB, Grant BF, Juan WJ, Smith SM, Saha TD. Antisocial personality disorder with childhood- vs. adolescence-onset conduct disorder: results from the National Epidemiologic Survey on Alcohol and Related Conditions. J Nerv Ment Dis 2006;194:667-75.

[28] Research Triangle Institute. Software for survey data analysis, SUDAAN. Version 9.0. Research triangle Park, NC: Research Triangle Institute; 2004

[29] Gottfredson MR, Hirsch TA. General theory of crime. Stanford, CA: Stanford University Press; 1990.

[30] DeLisi M. Career criminals in society. Thousand Oaks, CA: Sage; 2005. 